\title{
A subpopulation of mouse esophageal basal cells has properties of stem cells with the capacity for self-renewal and lineage specification
}

Jiri Kalabis, 1,2 Kenii Oyama 1,2 Takaomi Okawa, 1,2 Hiroshi Nakagawa, 1,2 Carmen Z Michaylira, 1,2 Douglas B. Stairs, ${ }^{1,2}$ Jose-Luiz Figueiredo, ${ }^{3}$ Umar Mahmood, ${ }^{3} \mathrm{~J}$. Alan Diehl, ${ }^{2,4}$ Meenhard Herlyn, ${ }^{5}$ and Anil K. Rustgi $1,2,6$

\begin{abstract}
1Division of Gastroenterology, Department of Medicine, and 2Abramson Cancer Center, University of Pennsylvania, Philadelphia, Pennsylvania, USA. ${ }^{3}$ Center for Molecular Imaging Research, Massachusetts General Hospital, Charlestown, Massachusetts, USA. ${ }^{4}$ Department of Cancer Biology and Abramson Family Cancer Research Institute, University of Pennsylvania, Philadelphia, Pennsylvania, USA. ${ }^{5}$ The Wistar Institute, Philadelphia,
\end{abstract} Pennsylvania, USA. ${ }^{6}$ Department of Genetics, University of Pennsylvania, Philadelphia, Pennsylvania, USA.

\begin{abstract}
The esophageal epithelium is a prototypical stratified squamous epithelium that exhibits an exquisite equilibrium between proliferation and differentiation. After basal cells proliferate, they migrate outward toward the luminal surface, undergo differentiation, and eventually slough due to apoptosis. The identification and characterization of stem cells responsible for the maintenance of the esophageal epithelium remains elusive. Here, we employed Hoechst dye extrusion and BrdU label-retaining assays to identify in mice a potential esophageal stem cell population that localizes to the basal cell compartment. The self-renewing capacity of this population was characterized using a clonogenic assay and a 3D organotypic culture model. The putative esophageal stem cells were also capable of epithelial reconstitution in vivo in direct esophageal epithelial injury models. In both the 3D organotypic culture and direct mucosal injury models, the putative stem cells gave rise to undifferentiated and differentiated cells. These studies therefore provide a basis for understanding the regenerative capacity and biology of the esophageal epithelium when it is faced with injurious insults.
\end{abstract}

\section{Introduction}

Stem cells are multipotent cells that have the ability to self-renew and generate transit amplifying cells through asymmetric division (1). Stem cells are believed to have additional intrinsic properties of apoptosis resistance and telomere maintenance and to participate in tissue homeostasis and regeneration throughout the lifespan of the organism.

A small subpopulation of stem cells maintains a hierarchy of cell lineage decisions in self-renewing tissues such as the testis, bone marrow, intestine, and skin (2-5). The most widely accepted criteria for keratinocyte stem cells are slow-cycling growth, selfrenewal capacity, and a high proliferative potential activated by wounding or in tissue culture (6). The slow-cycling cells have been experimentally designated label-retaining cells (LRCs) in the epidermis, where a small subset of keratinocytes has been shown to retain ${ }^{3} \mathrm{H}$-thymidine or BrdU for several months (7). These cells were found to be either basally positioned keratinocytes or nonkeratinocytes of the Langerhans cell type that lie suprabasally except in the epidermis, where they are present in low numbers, occupy a similar position as label-retaining keratinocytes (8), and are mainly localized to the bulge of hair follicles (9). Some integrin molecules, such as the $\beta 1$ and $\alpha 6$ subunits, have been suggested to be stem cell markers for keratinocytes as well as spermatogonial

Nonstandard abbreviations used: CK, cytokeratin; KSFM, keratinocyte serum-free medium; LRC, label-retaining cell; NSP, non-side population; SP, side population. Conflict of interest: The authors have declared that no conflict of interest exists. Citation for this article: J. Clin. Invest. doi:10.1172/JCI35012. cells of the testis (10-12). $\beta 1$ integrin-enriched basal keratinocytes adhere more rapidly to some ECM components and have high colony formation efficiency. LRCs isolated from the mouse ear epidermis were shown to be present in a cell fraction capable of rapid adherence to collagen type IV (13).

Esophageal stem cells are thought to reside within the basal layer of the stratified squamous epithelium (14). Asymmetric cell division was observed in the interpapillary zone of the basal layer of the human esophageal epithelium, suggesting but not establishing the presence of self-renewing stem cells and transit-amplifying cells (15). However, the isolation and characterization of esophageal stem cells have remained elusive. Their identification could have implications upon similar stem cell populations in stratified squamous epithelia of the oral cavity, larynx, trachea, and anogenital tract. Hematopoietic stem cells have been defined as a side population (SP) with the ability to exclude Hoechst 33342 DNA binding dye mediated by the ABCG2 transporter (16). The Hoechst 33342 dye efflux test has been applied to explore stem cells of epidermal keratinocytes, mammary epithelial cells, and pancreatic $\beta$ cells (17-21). Using this approach, we have identified such a subpopulation in the mouse esophageal epithelium. Through the development of what we believe are novel clonogenic assays and 3D organotypic culture models, we have characterized SP cells that have properties consistent with self-renewal and give rise to differentiated suprabasal cells in a 3D organotypic culture. Furthermore, The $\mathrm{CD} 34^{+}$fraction of SP cells participate in epithelial regeneration (differentiated suprabasal cells) in an innovative murine esophageal mucosal injury model. 


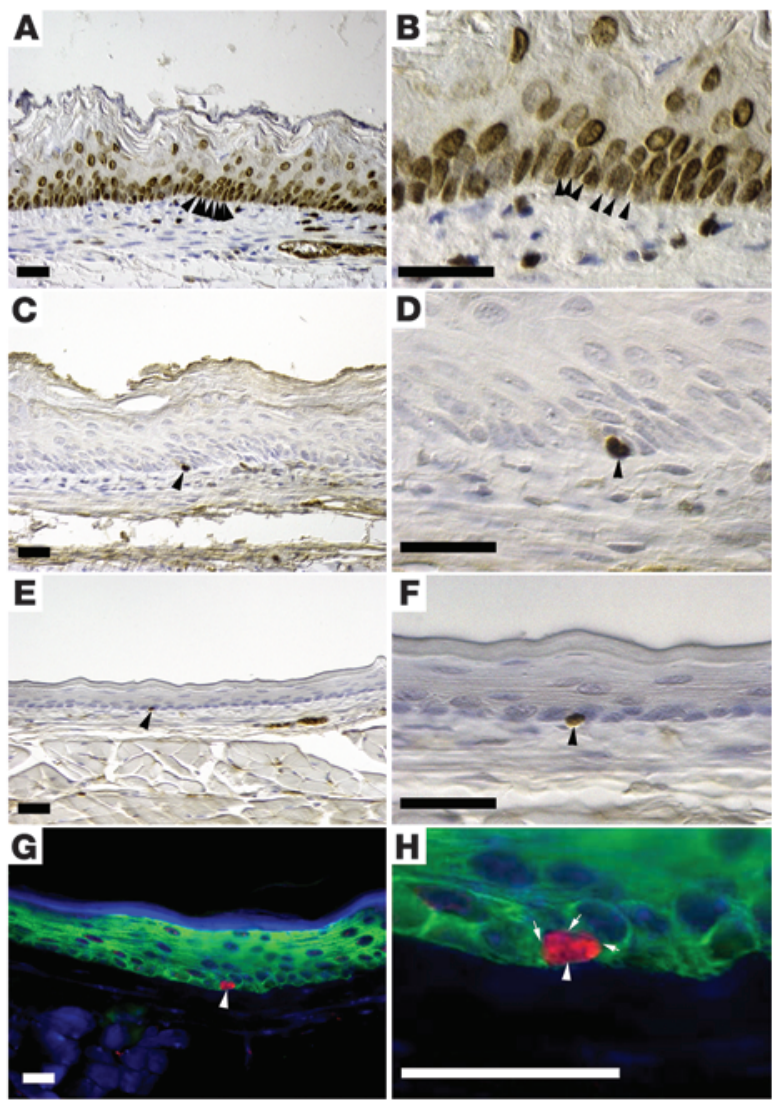

\section{Results}

Slow-cycling cells (keratinocytes) reside in the basal layer of the squamous esophageal epithelium. The BrdU or ${ }^{3} \mathrm{H}$-thymidine retention method was used previously to detect potential slow-cycling stem cell populations in other tissues $(9,22)$. In mice (age 1 month) treated with BrdU continuously for 4 weeks, nearly $100 \%$ of nuclei in the basal and suprabasal layers of the squamous esophageal epithelium were $\mathrm{BrdU}^{+}$at the end of BrdU administration (Figure 1). A limited number of $\mathrm{BrdU}^{+}$LRCs remained in the esophageal basal cell compartment 2 and 4 weeks after BrdU withdrawal (Figure 1). The LRCs were positioned in apposition to the basement membrane with nuclei that appeared to be smaller than nuclei of the surrounding epithelial cells. There were no positive LRCs localized in the submucosal glands. The LRCs were characterized as epithelial cells based upon colocalization of both BrdU and cytokeratin (CK) (Figure 1). When the LRCs were quantified using the esophagi of mice 4 weeks after BrdU withdrawal ( $n=5$ mice), there were more LRCs in the distal esophagus (Supplemental Figure 1; supplemental material available online with this article; doi:10.1172/JCI35012DS1).

A SP is detected in esophageal keratinocytes. SP cells have been shown to have properties consistent with those of a stem cell-enriched population in other tissues (23). Freshly isolated mouse esophageal epithelial cells were stained with $5 \mu \mathrm{g} / \mathrm{ml}$ of Hoechst 33342 dye for 90 minutes at $37^{\circ} \mathrm{C}$ and subjected to flow cytometry-based sorting. When cells were sorted based on size (forward and side scatter) and Hoechst 33342 dye characteristics, there was a characteristic SP, defined by low fluorescence for Hoechst 33342 blue and red (Figure 2). The SP cells were abolished by the addition of verapamil, an inhibitor of the channel responsible for the medi-

\section{Figure 1}

BrdU LRCs reside in the basal compartment. (A and B) After 1 month of BrdU administration and immediate processing of tissues, almost all basal cells were $\mathrm{BrdU}^{+}$(arrowheads). Original magnification, $\times 100(\mathbf{A})$, $\times 400$ (B). (C-F) BrdU+ cells (arrowheads) were restricted in their spatial localization after 1 month of BrdU administration and 2 weeks (C and $\mathbf{D})$ and 4 weeks (E and $\mathbf{F}$ ) of tissue processing after cessation of BrdU administration. Original magnification, $\times 100$ (C and E), $\times 400$ (D and $\mathbf{F}$ ). ( $\mathbf{G}$ and $\mathbf{H}$ ) Immunofluorescence revealed that $\mathrm{BrdU}^{+}$cells (red; arrowhead) were pan-CK+ (green; arrows), establishing their epithelial origin. Nuclei were counterstained with DAPI. Original magnification, $\times 100(\mathbf{G}), \times 400(\mathbf{H})$. Scale bars: $25 \mu \mathrm{m}$.

ated action of ABCG2 (Figure 2). The SP cells were also established to be epithelial in origin and did not emerge directly from the mesenchymal compartment (Figure 2).

LRCs are enriched in the SP of isolated esophageal cells. As both LRCs and the SP may harbor stem cells, it was a formal possibility that some LRCs might have SP characteristics. Therefore, mouse esophageal keratinocytes isolated from BrdU-treated mice at various times after BrdU withdrawal were sorted as SP cells. When the SP cells were immunostained with BrdU, there were $35 \% \pm 2.27 \%$ vs. $0.5 \% \pm 0.41 \% \mathrm{BrdU}^{+}$cells in SP- vs. non-SP-sorted (NSP-sorted) cells $\left(P<10^{-10}, n=6\right.$ experiments) at 2 weeks after BrdU withdrawal. At 4 weeks (Figure 2), no $\mathrm{BrdU}^{+}$cells were detected in the NSP cells, but they represented $9 \% \pm 2.1 \%$ of the SP cells in the esophagus $\left(P<10^{-4}, n=6\right.$ experiments). Thus, the $\mathrm{SP}$ was localized to the sites of BrdU retention in the basal cell compartment of the esophageal epithelium.

The cells of the SP express the hematopoietic stem cell marker CD34 but do not express certain putative epidermal stem cell markers. To determine whether esophageal SP cells have the same stem cell markers as epidermal or bone marrow stem cells, we analyzed integrin $\beta 1$ (CD29), integrin $\alpha 6$ (CD49f), and transferrin receptor (CD71) as potential epidermal keratinocyte stem cell markers, as well as the sarcoendoplasmic reticulum calcium ATPase family member (Sca-1) (24) and CD34 as bone marrow stem cell markers (Figure 3). There were higher percentages of $\mathrm{CD} 29^{+}$and $\mathrm{CD} 49 \mathrm{f}^{+} \mathrm{CD} 71^{-}$cells in epidermal SP cells than in total epidermal cells (CD29+, 85\% vs. 74\%;

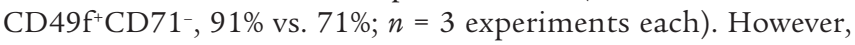
percentages of both $\mathrm{CD} 29^{+}$and $\mathrm{CD} 49 \mathrm{f}^{+} \mathrm{CD} 71^{-}$cells were lower in esophageal SP cells compared with total esophageal epithelial cells (Figure 3). This was confirmed by RT-PCR (Figure 3).

The percentage of Sca- $1^{+}$cells was higher in bone marrow SP than in total bone marrow ( $40 \%$ vs. $6 \%$ ) but lower in esophageal SP cells compared with total esophageal cells (86\% vs. $99.6 \%$; Figure $3 ; n=3$ experiments). The percentage of CD $34^{+}$cells in bone marrow SP was higher than in total bone marrow, and there was a significantly higher percentage of $\mathrm{CD} 34^{+}$cells in the esophageal SP cells than in total esophageal cells (34\% vs. $0.4 \%$; Figure $3 ; n=5$ experiments). These results suggest that CD34 is a candidate for the potential esophageal stem cell population.

Concurrently, we excluded hematopoietic cells as a source contributing to the esophageal SP. To that end, the esophageal SP was not enriched with CD45, a hematopoietic cell marker (data not shown). We also wished to determine whether bone marrowderived cells might contribute to esophageal epithelial homeostasis. Recipient mice of FVB/N background (ages 2-3 months) were irradiated with $12 \mathrm{~Gy}$ (i.e., 6 Gy twice with 3-hour intervals) and reconstituted with $2-3 \times 10^{6}$ of whole bone marrow cells from 
A

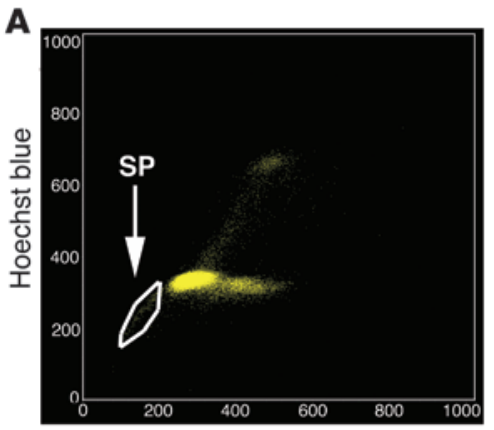

Hoechst red

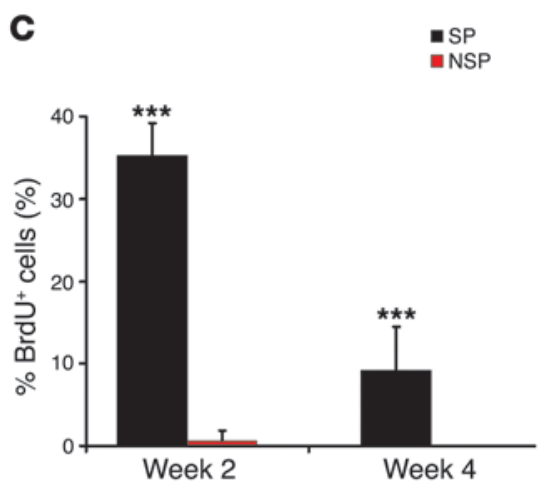

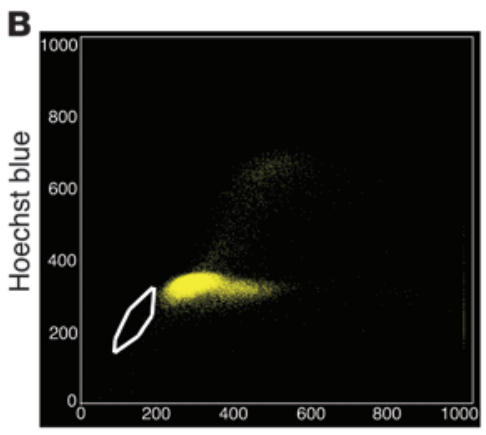

Hoechst red

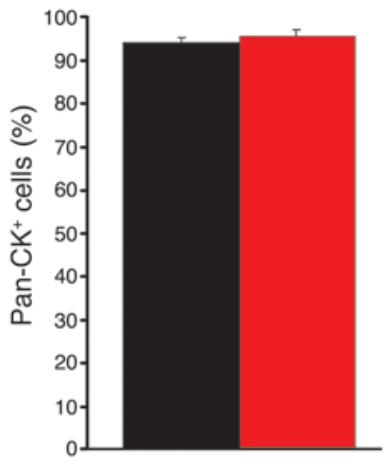

\section{Figure 2}

Esophageal epithelial cell SP is present with Hoechst 33352 dye extrusion. (A) Freshly isolated mouse esophageal epithelial cells were stained with Hoechst 33342 dye and subjected to flow cytometry-based cell sorting. When cells were sorted based upon size (forward and side scatter), there was a characteristic SP (outlined region), defined by low fluorescence for both Hoechst 33342 red and Hoechst 33342 blue. (B) SP cells were abolished with administration of verapamil (outlined region). (C) Left: The percentage of $\mathrm{BrdU}^{+}$cells was substantially higher in SP cells than in NSP cells at weeks 2 and 4. Right: SP and NSP cells were pan- $\mathrm{CK}^{+}$when quantified (SP, $94.8 \% \pm 1.6 \%$; NSP, $91.6 \% \pm 1.38 \%)$. ${ }^{* \star *} P<0.001$. donor ROSA26-EGFP mice of FVB/N background via a single tail vein injection. The overall level of bone marrow engraftment was confirmed to be more than $95 \% \mathrm{GFP}^{+}$. $\mathrm{GFP}^{+}$cells were found in the small intestine (Peyer's patches) and colon, but not in the esophagus, suggesting that bone marrow-derived cells do not contribute to putative esophageal stem cells (Supplemental Figure 2).

The esophageal SP has properties consistent with stem cells or progenitor cells. When the esophageal SP and NSP cells were seeded onto irradiated Swiss $3 \mathrm{~T} 3$ cells and cultivated for 4 weeks, epithelial colonies emerged from the SP but not from the NSP. This difference was dramatic in the colony formation assays and was independent of the number of cells seeded (Figure 4; $P<0.001$, $n=3$ experiments). To test further the functional properties of the esophageal SP, we developed a mouse esophageal organotypic (3D) culture system. In such a context, the microenvironment is recapitulated through the creation of a stratified epithelium, basement membrane, and ECM mixed with fibroblasts (25). When SP or NSP cells, isolated from GFP mice, were seeded on top of the ECM, only the SP $\mathrm{GFP}^{+}$cells led to the formation of a mature epithelium, suggesting that such cells could give rise to transient amplifying (TA) cells, culminating in differentiation. Two-photon confocal microscopy further revealed that the SP $\mathrm{GFP}^{+}$cells formed colonies on top of the epithelium to a much greater extent than did NSP GFP+ cells (Figure 4).

While $1 \times 10^{5}$ freshly isolated unsorted esophageal cells seeded alone formed an epithelium, this was not the case with $3 \times 10^{4}$ freshly isolated cells, suggesting a threshold of programmed cells are required for differentiated cells in this model system. We next took SP or NSP cells from $\mathrm{GFP}^{+}$mice, and mixed with $3 \times 10^{4}$ freshly isolated esophageal cells from WT mice (negative for GFP), thereby creating conditions that would reveal whether SP GFP cells could form an epithelium in this context. These WT-derived cells were GFP- (Figure 4, F and G). When SP GFP+ cells were mixed with unsorted $\mathrm{GFP}^{-}$cells, there was a complete epithelial layer present on day 12 (Figure 4). This was not the case with NSP GFP cells mixed with unsorted GFP- cells (Figure 4).

In order to determine whether the $\mathrm{SP} \mathrm{GFP}^{+}$cells could give rise to differentiated cells in organotypic culture, we performed immunohistochemistry for CK14, a marker of proliferating basal cells, and for CK4 and CK13, markers of differentiated suprabasal cells. Figure 5 reveals that the epithelium emerging from SP GFP ${ }^{+}$ cells is $\mathrm{CK}_{14} 4^{+}$(Figure 5G) and $\mathrm{CK} 4^{+} \mathrm{CK} 13^{+}$(Figure 5, $\mathrm{H}$ and I). However, this was not evident in the incomplete epithelial in organotypic cultures with control cells (Figure 5, A-C) or the NSP $\mathrm{GFP}^{+}$cells (Figure 5, D-F).

We next evaluated the capacity of properties associated with self-renewal of SP GFP cells in organotypic culture through serial transplantation. In this context, the epithelium from the initial organotypic culture was harvested and used to create a second organotypic culture with successful epithelial formation and evidence of $\mathrm{GFP}^{+} \mathrm{Ki} 67^{+} \mathrm{CK} 14^{+} \mathrm{CK} 4^{-} \mathrm{CK} 13^{-}$basal cells and $\mathrm{GFP}^{+} \mathrm{Ki}^{-} 7^{-}$ $\mathrm{CK} 14^{-} \mathrm{CK} 4^{+} \mathrm{CK} 13^{+}$suprabasal cells (Figure 6, M-R). However, control cells and NSP GFP ${ }^{+}$cells did not form complete epithelia (there were only minimal clusters of poorly ordered cells) without evidence of basal and suprabasal compartments (Figure 6, A-L).

In aggregate, the esophageal SP cells formed colonies in a clonogenic assay as well as a mature, complete epithelium in organotypic culture with serial passage, with the latter showing evidence of differentiated suprabasal cells. These functional properties are consistent with a potential stem cell or progenitor cell population.

CD34 is a marker for esophageal stem cells. To test whether CD34 is a functionally relevant marker for the putative esophageal stem cells, CD $34^{+}$cells were functionally compared with CD34- cells in vitro and in vivo. The $\mathrm{CD} 34^{+}$and $\mathrm{CD} 34^{-}$cells were $\mathrm{CK}^{+}$, ensuring their pure epithelial, nonhematopoietic origin (Figure 7 ). In the colony formation assay, $\mathrm{CD} 34^{+}$cells retained the ability to form 

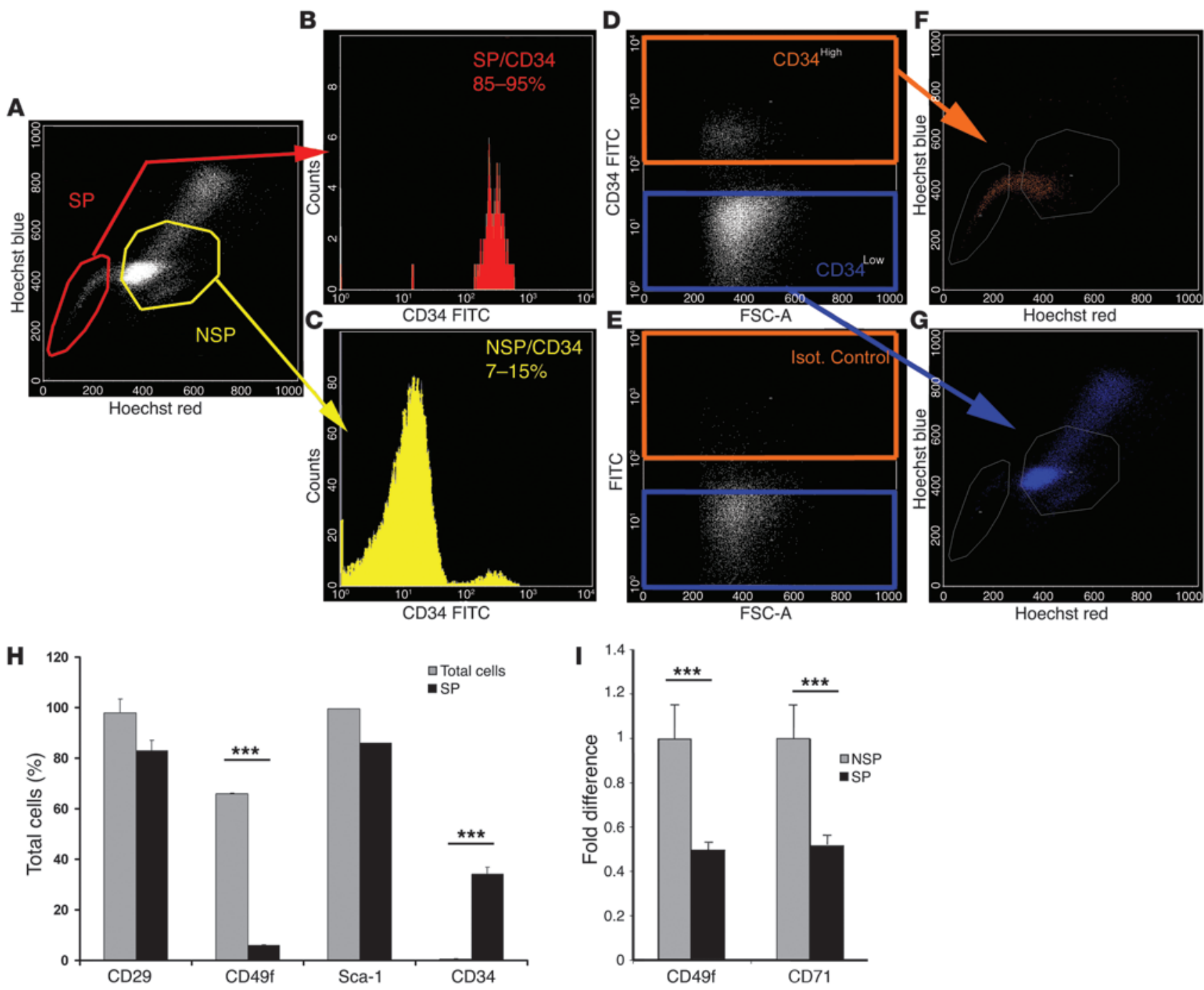

\section{Figure 3}

CD34 is a marker of esophageal epithelial SP cells. Freshly isolated esophageal keratinocytes were stained with Hoechst and CD34. (A) SP (outlined in red) and NSP (outlined in yellow) cells. (B) SP cells were highly positive (85\%-95\%) for CD34, and (C) the NSP cells were CD34lo (7\%-15\% positive). Similarly, when cells were sorted based upon CD34 expression (D), CD34 ${ }^{\text {hi }}$ cells (orange) accumulated mostly in the original SP area of the Hoechst red/blue plot (F), while CD34lo cells (blue) accumulated mostly in the NSP area (G). (E) Isotype antibody control. (H) Quantitation of FACS expression of CD29, CD49f, Sca-1, and CD34 on SP versus total cells (*** $P<0.001 ; n=3$ for CD29, CD49f, and Sca-1; $n=5$ for CD34). (I) Fold difference of CD49f and CD71 expression in SP cells compared with NSP cells, analyzed using RT-PCR. ${ }^{* * \star} P<0.001$, $n=3)$. Data represent mean \pm SEM.

colonies in comparison with CD34- cells (Figure 7; $P<0.001, n=3$ experiments). The expression of both CD34 and ABCG2 in SP cells (vs. NSP cells) was confirmed by microarray analysis (data not shown) and real-time PCR (Figure 7). Of note, the EphA3 receptor, which is involved in cell-cell communication, was notably and preferentially expressed in SP cells (Figure 5).

To establish a role for the esophageal SP cells as potential stem cells in vivo, a new esophageal epithelial injury model was developed through mechanical mediated injury of the esophageal epithelium in mice, designated as time point 0 . We found that the epithelium is reconstituted 48 hours after injury (data not shown). To evaluate the possible role of recruitment of $\mathrm{CD} 4^{+}$cells in participating in epithelium reconstitution fol- lowing injury, 3 cohorts of mice were used. Control (PBS injection only into the submucosa), $\mathrm{CD} 34-\mathrm{GFP}^{+}$, or $\mathrm{CD} 34^{+} \mathrm{GFP}^{+}$cells were injected into the submucosa or subepithelial compartment after the initial mechanically induced epithelial injury. The mice were sacrificed 48 hours after injection for histological and GFP immunohistochemical evaluation. Only the $\mathrm{CD} 34^{+} \mathrm{GFP}^{+}$cells participated in reconstitution of the epithelium after injury, that is, $\mathrm{GFP}^{+}$cells were found 48 hours after injection in the epithelium (Figure 7, F and G) and the $\mathrm{GFP}^{+}$cells co-stained with CK14 and CK4 (Supplemental Figure 3). Such was not the case in control (Figure 7, D and G) or CD34- $\mathrm{GFP}^{+}$cells (Figure 7, E and H).

As a parallel consideration, epithelioid cyst formation upon intraepidermal injection of putative stem cells into immuno- 
$\mathbf{A}$
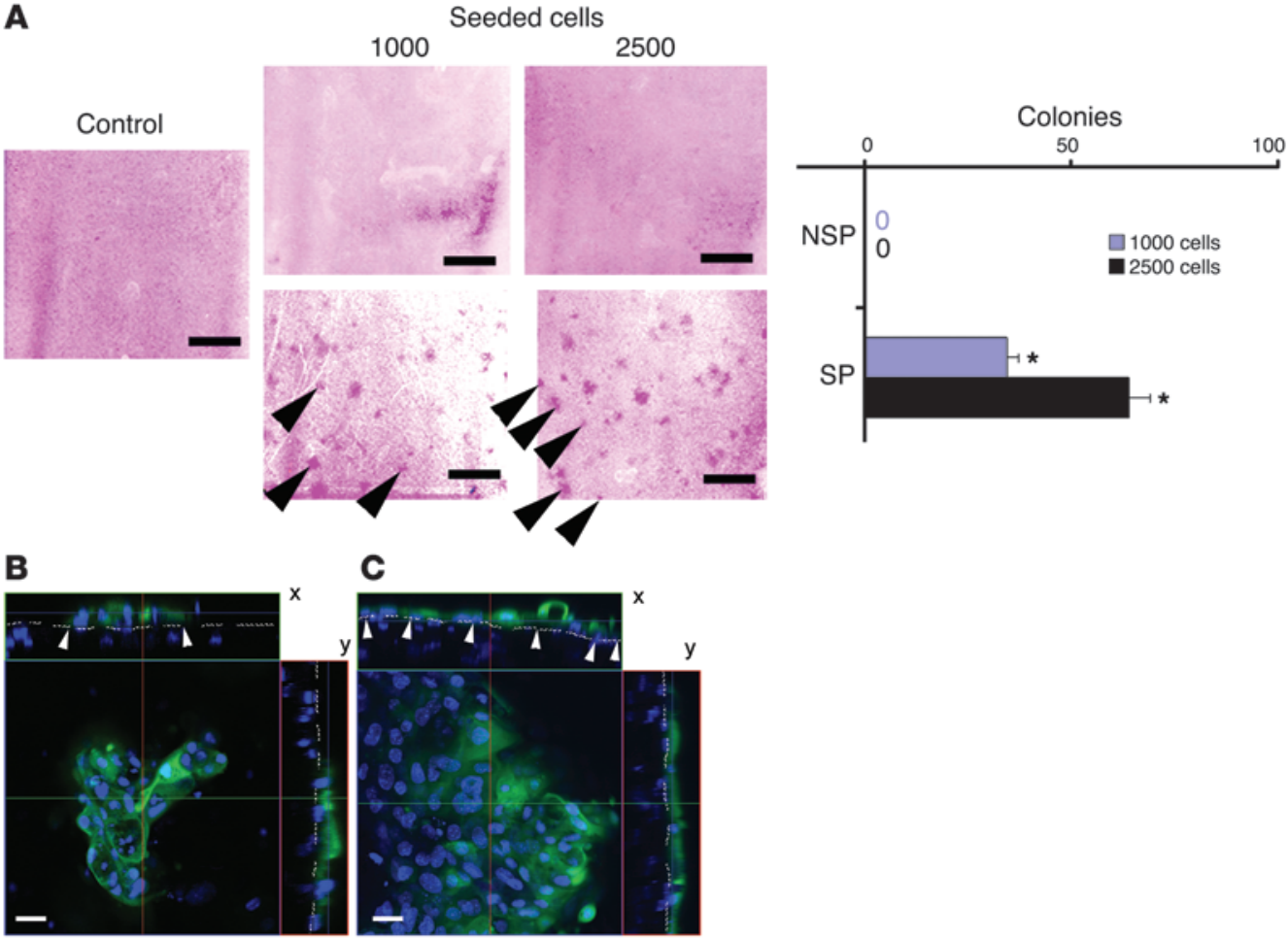

C
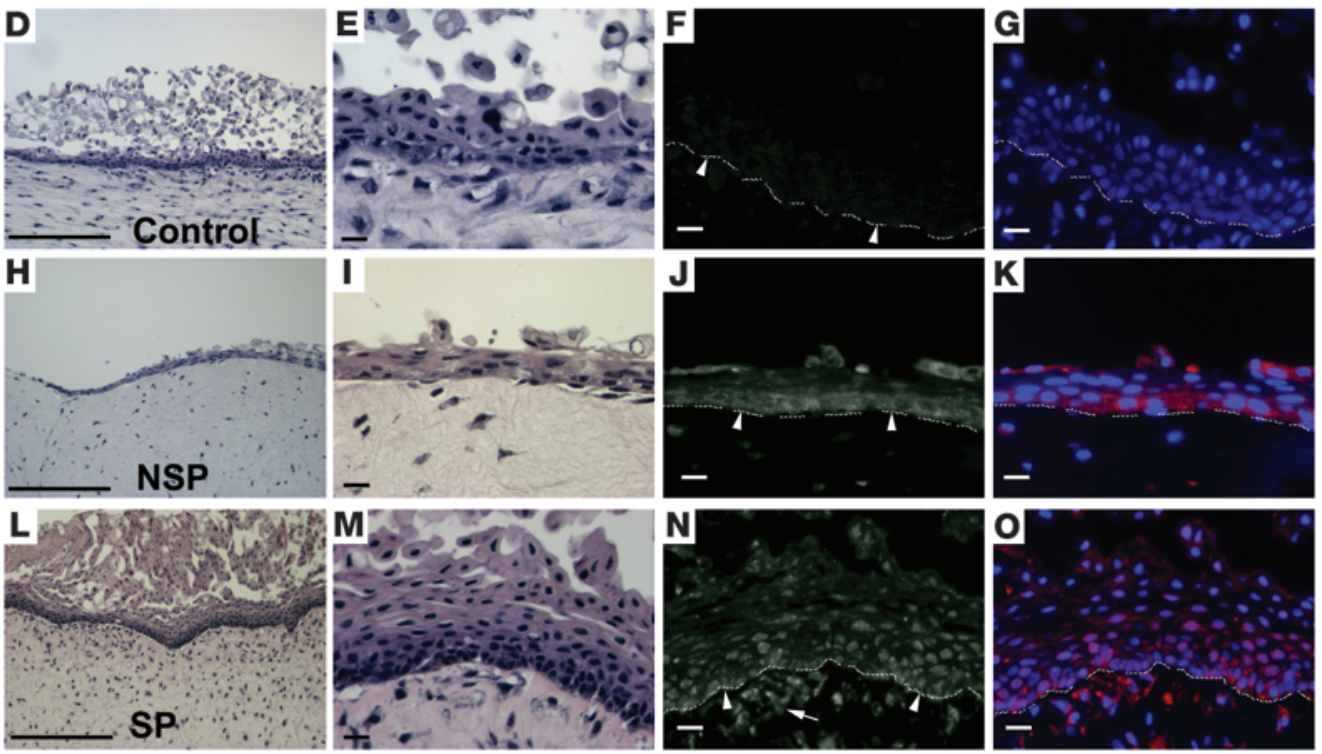

\section{Figure 4}

SP cells have stem cell properties in clonogenic and in 3D organotypic culture assays. (A) When SP, NSP, and unsorted control cells were grown for 4 weeks, there were $34.33 \pm 2.84$ colonies with 1,000 SP cells and $64 \pm 4.93$ colonies with 2,500 SP cells $(n=3$ experiments), compared with absent colonies with control or NSP cells ( $n=3$ experiments). Arrowheads indicate colonies. ${ }^{\star} P<0.001$ compared with NSP. (B) Two-photon microscopy of the disordered cells on the organotypic culture (day 12) after seeding $10^{3} \mathrm{NSP}$ cells isolated from GFP+ mice (green) with DAPI ${ }^{+}$ nuclei (blue); top view, z-stack, $53.8 \mu \mathrm{m}$ in $0.78-\mu \mathrm{m}$ increments. (C) Two-photon microscopy of the fully formed epithelium on day 12 after seeding $10^{3} \mathrm{SP}$ cells isolated from GFP+ mice (green) with DAPI+ nuclei (blue); top view, z-stack, $60 \mu \mathrm{m}$ in 1- $\mu \mathrm{m}$ increments. Arrowheads indicate basement membrane. (D and E) Unsorted GFP- cells $\left(3 \times 10^{4}\right)$ did not form a complete epithelium. (F) GFP- immunohistochemistry and $(\mathbf{G}) \mathbf{D A P I}^{+}$ nuclei. (H and I) Sorted $10^{3}$ NSP cells from GFP+ mice mixed with $3 \times 10^{4}$ unsorted GFP- cells did not form a complete epithelium. (J) Mosaic GFP+ pattern and (K) DAPI+ nuclei. ( $\mathbf{L}$ and $\mathbf{M})$ SP cells $\left(10^{3}\right)$ from GFP+ mice mixed with $3 \times 10^{4}$ unsorted GFP- cells. There was complete epithelial formation with keratinization. (N) GFP+ immunohistochemistry and (O) DAPI+ nuclei. Dotted line in $\mathbf{B}-\mathbf{O}$ indicates basement membrane. Scale bars: $5 \mathrm{~mm}(\mathbf{A}), 25 \mu \mathrm{m}(\mathbf{B}-\mathbf{0})$. Original magnification, $\times 20(\mathbf{A}) ; \times 100(\mathbf{D}, \mathbf{H}$, and L); $\times 200$ (B and C); ×400 (E-G, I-K, and M-O). 

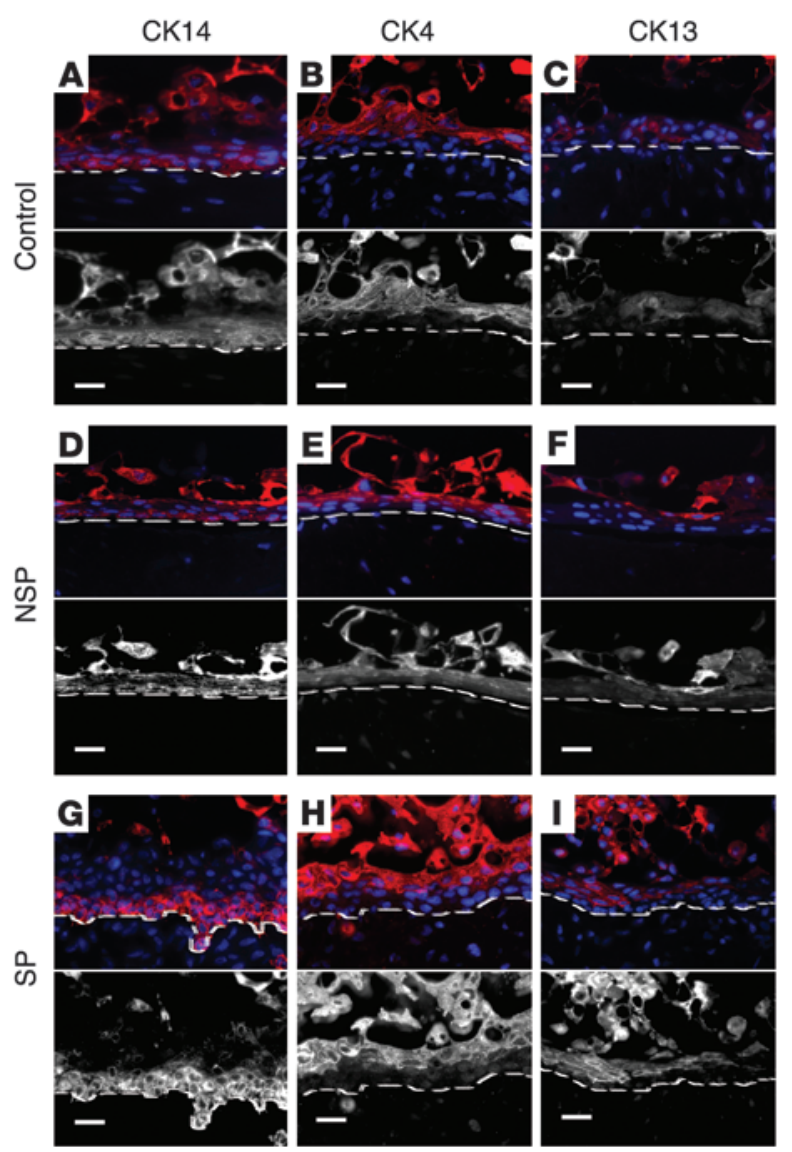

deficient mice has been used as a basis to designate stem cells (26). Indeed, when SP cells or CD $34^{+}$cells were injected dermally into recipient mice, epithelioid cysts formed, a reaction not observed with the injection of NSP or CD34- cells (data not shown).

\section{Discussion}

Nucleotide label retention has been proposed to be a property of keratinocyte stem cells, also known as LRCs. In the esophagus, we found that about $1 \%$ of basal cells were LRCs, with an increasing gradient from the proximal to the distal esophagus. Multipotent skin stem cells are thought to be localized in the basal layer or the hair follicle bulge area, where they have been detected by labeling skin with ${ }^{3} \mathrm{H}$-thymidine or $\operatorname{BrdU}(9,27,28)$ and/or colony formation in culture (29). These cells were shown to contribute to epithelial regeneration because of their ability to regenerate both glands and the epidermis. There are also solitary BrdU- or ${ }^{3} \mathrm{H}$-thymidine-retaining cells in the interfollicular regions of mice $(9,30$, $31)$. The extent to which these interfollicular, $\beta 1$ integrin-positive cells (12) can contribute to the pluripotent renewal of the skin remains to be established.

SP cells were first discovered in the hematopoietic system (16). They are now considered primitive stem cells. Since then, SP cells have been found in several tissues and experimental cell lines, including bone marrow, muscle, lung, mammary epithelium, embryonic stem cells, and neurosphere cells $(23,24)$. Thus, the SP phenotype may identify a subset of stem cells. SP cells from bone marrow have been shown to be able to rescue lethally irradiated mice and to differentiate into both lymphoid and myeloid

\section{Figure 5}

SP cells are able to differentiate in organotypic culture, giving rise to proliferative basal CK14+CK13-CK4- and differentiated suprabasal CK14-CK13 ${ }^{+}$CK4 $4+$ cells. (A-C) Unsorted freshly isolated WT (GFP-) cells did not form an epithelium layer (similar to data shown in Figure 4) with immunohistochemical staining for (A) CK14, (B) CK4, and (C) CK13. (D-F) Sorted $10^{3}$ NSP cells from GFP ${ }^{+}$mice mixed with $3 \times 10^{4}$ unsorted GFP- cells did not form an epithelium (similar to data shown in Figure 4) with immunohistochemical staining for (D) CK14, (E) CK4, and $(\mathbf{F})$ CK13. (G-I) SP cells $\left(10^{3}\right)$ from GFP+ mice mixed with $3 \times 10^{4}$ unsorted GFP- cells formed a complete epithelium with luminal keratinization (similar to data shown in Figure 4) with well-defined proliferative basal and differentiated suprabasal cells. Immunohistochemical staining for (G) CK14, (H) CK4, and (I) CK13. Dashed lines indicate the basement membrane. Original magnification, $\times 400$. Scale bar: $25 \mu \mathrm{m}$.

lineages (16). Interestingly, when SP cells were isolated from mice treated with BrdU in our experiments, there was accumulation of $\mathrm{BrdU}^{+}$cells in the SP fraction. Furthermore, the $\mathrm{BrdU}^{+}$fraction of SP cells was localized to the basal cell compartment. Stem cells are thought to be relatively dormant, especially in comparison with transient amplifying cells. In agreement with this concept, as they proliferate even at a slow rate, they lose BrdU slowly. The actual numbers of stem cells is therefore likely underrepresented when approximated as a $\mathrm{BrdU}^{+}$population.

LRCs remain a very valuable tool to pinpoint the anatomical localization of stem cells in the skin (9). The localization of pluripotent stem cells of the bulge area of the hair follicle has been confirmed genetically using the K15 promoter (32). Interestingly, although the esophageal squamous epithelium is morphologically similar to the epidermis, the LRCs of the esophagus reside in the basal cell layer or compartment. Furthermore, SP cells (Hoechst dye extrusion) or $\mathrm{CD} 34^{+}$cells can form colonies, and the SP cells can form a mature, differentiated $\left(\mathrm{CK}^{+} \mathrm{CK} 13^{+}\right)$epithelium in organotypic (3D) culture, including with serial transplantation. These results suggest the SP cells as well as the $\mathrm{CD} 34^{+}$fraction of the SP cells have the capacity for self-renewal in the model systems used.

SP cells from bone marrow and skeletal muscles express Sca-1 (24), and SP cells from mammary epithelium express $\alpha 6$ integrin (33), which we did not find preferentially expressed in the esophageal SP. Furthermore, $\operatorname{Lgr} 5$ (leucine-rich repeat-containing $\mathrm{G}$ protein-coupled receptor 5), a marker of intestinal stem cells (34) and potentially a marker of other tissue stem cells, was not found in our microarray analysis (data not shown). Lgr5 is found in the bulge of the hair follicle but not in the epidermis $(34,35)$, but its potential role in the esophageal epithelium remains possible. However, there was robust and preferential expression of CD34 in the esophageal SP. These results indicate that, unlike $\mathrm{CD} 29^{+}$and $\mathrm{CD} 49 \mathrm{f}^{+} \mathrm{CD} 71^{-}$or Sca- $1^{+}$populations, $\mathrm{CD} 34^{+}$cells are enriched in the esophageal SP. CD34 has been demonstrated to be a marker for the hair follicle bulge $(36,37)$ and may act as a negative regulator of cell adhesion in hematopoietic cells (38). CD34+ cells were found to be able to migrate and repopulate the esophageal epithelium following injury and co-stained with CK4 in the differentiated suprabasal cells. This is consistent with the notion that tissue repair and regeneration may involve the selective recruitment of circulating or resident stem cell populations. We believe that our in vitro and in vivo experiments establish the existence of a subpopulation of basal cells in the esophageal epithelium that have self-renewal properties and the capacity to give rise to differentiated suprabasal cells, consistent 


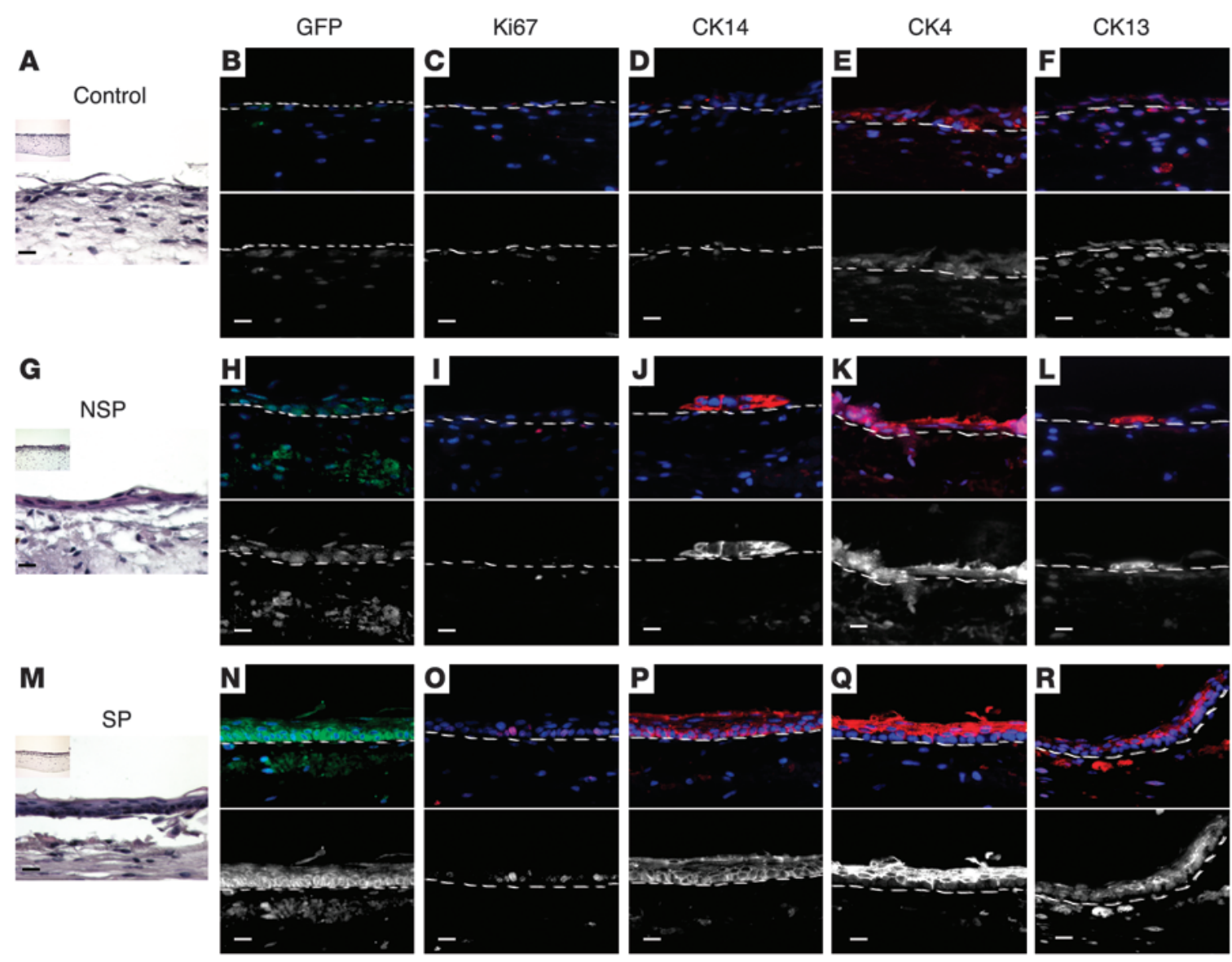

\section{Figure 6}

SP GFP+ derived cells form a complete epithelium in organotypic culture upon serial passage. Samples were harvested with trypsin after formation of the primary epithelium (described in Figures 4 and 5) and harvested again after the initial organotypic culture for the second organotypic culture. (A) There were only a few scattered epithelial cells in serial samples prepared form the organotypic cultures of unsorted WT (GFP-) cells (H\&E staining). (B-F) Immunohistochemistry revealed that the cells were GFP- (B), Ki67- (C), CK14- (D), CK4- (E), and CK13- (F). (G) Only a few isolated clusters of epithelial cells did not form an epithelium from $10^{3} \mathrm{NSP}$ cells from GFP+ mice mixed with $3 \times 10^{4}$ unsorted GFP- cells (H\&E staining). (H-L) Immunohistochemistry revealed that the cells were mostly GFP- $(\mathbf{H})$, Ki67- (I), minimally and irregularly CK14+ $(\mathrm{J})$ and $\mathrm{CK}^{+}(\mathbf{K})$, and $\mathrm{CK} 13^{+}(\mathbf{L})$. (M) A complete epithelium formed, derived from sorted $10^{3}$ SP cells from GFP+ mice mixed with $3 \times 10^{4}$ unsorted GFP- cells (H\&E staining). (N-R) Immunohistochemistry revealed that cells were GFP+ $(\mathbf{N})$, basal cells were $\mathrm{Ki}^{+} 7^{+}(\mathbf{O})$ and $\mathrm{CK} 14^{+}(\mathbf{P})$, and suprabasal cells were $\mathrm{CK}^{+}(\mathbf{Q})$ and $\mathrm{CK}_{13}{ }^{+}(\mathbf{R})$. Dashed line represents basement membrane. Original magnification, $\times 100$ (insets in $\mathbf{A}, \mathbf{G}$, and M); $\times 400$ (B-F, H-L, and $\mathbf{N}-\mathbf{R})$. Scale bars: $25 \mu \mathrm{m}$.

with the possibility that these basal cells include stem or progenitor cells. It should be noted that the presence of even one type of progenitor cell might maintain a normal, mature epidermis (39).

\section{Methods}

BrdU labeling. Adult C57BL/6 mice were pulse-labeled by administering BrdU (Sigma-Aldrich) at $0.8 \mathrm{mg} / \mathrm{ml}$ in drinking water ad libitum continuously for 4 weeks. At the times indicated in the Results, mice were sacrificed and their esophagi were collected and fixed in 4\% PFA. Esophageal tissues from WT mice were used as controls. For detecting BrdU LRCs, the esophagus was analyzed longitudinally and transversally. All animal studies in this section and subsequent sections were approved by the Institutional Animal Care and Use Committee of the University of Pennsylvania.

Isolation of primary mouse esophageal keratinocytes. The esophagi were isolated from young mice (2-4 months), opened longitudinally, washed in PBS, and incubated with $0.6-1.0 \mathrm{U} / \mathrm{ml}$ of Dispase 1 (Roche) for 15 minutes at $37^{\circ} \mathrm{C}$, and epithelial sheets were stripped from mesenchymal tissues using forceps. The epithelial sheets were minced with a scalpel and incubated with $0.05 \%$ trypsin/EDTA (Gibco) for 10 minutes at $37^{\circ} \mathrm{C}$. The trypsin was then quenched with $200 \mu \mathrm{g} / \mathrm{ml}$ soybean trypsin inhibitor (Sigma-Aldrich) and the suspension passed through a $40-\mu \mathrm{m}$ cell strainer (Becton Dickinson). Cells were centrifuged and resuspended in keratinocyte serum-free medium (KSFM; Gibco) with EGF ( $1 \mathrm{ng} / \mathrm{ml})$, BPE $(50 \mathrm{mg} / \mathrm{ml})$, and $2 \%$ FBS and $10 \mathrm{mM}$ HEPES.

Hoechst 33342 staining and flow cytometry. Esophageal keratinocytes $\left(10^{6}\right.$ cells $/ \mathrm{ml}$ ) were stained at $37^{\circ} \mathrm{C}$ with $5 \mu \mathrm{g} / \mathrm{ml}$ of Hoechst 33342 (SigmaAldrich) in KSFM for 90 min. Hoechst exclusion was inhibited by adding $50 \mu \mathrm{M}$ verapamil. Cells were resuspended with $100 \mu \mathrm{g} / \mathrm{ml}$ propidium iodide (Invitrogen) to exclude dead cells and sorted on a FACSDiva (BD Biosciences) at 50 psi. Hoechst-DNA binding was detected by excitation with a UV laser ( $355 \mathrm{~nm}$ at $50 \mathrm{~mW}$ ), followed by a 610 -nm short-pass dichroic mirror and 670 LP and 450 BP 20 detection filters for red and blue emission wavelengths, respectively. For antibody staining, cells were incubated with primary antibodies for 30 minutes on ice after Hoechst 

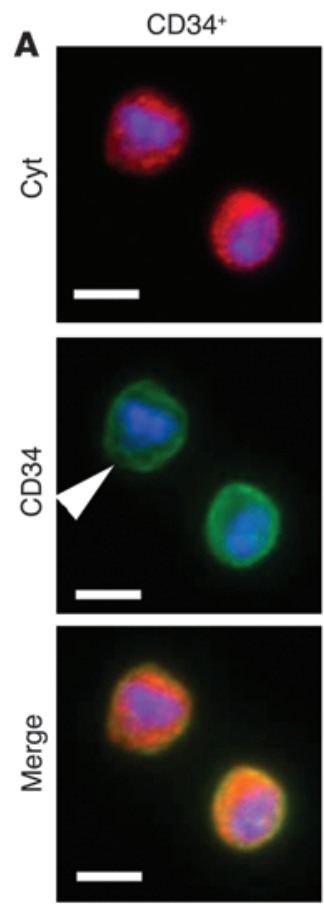

$\mathrm{CD}^{-} 4^{-}$
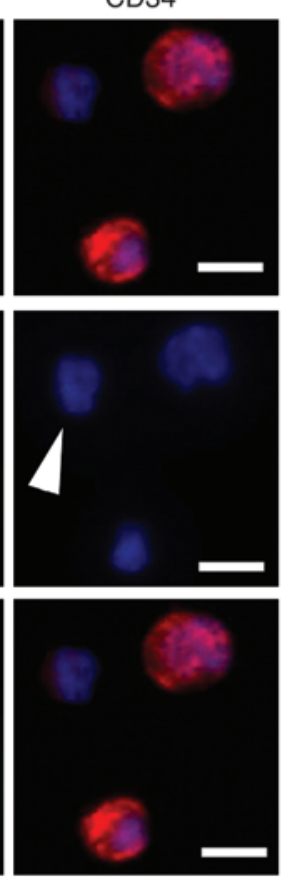

B

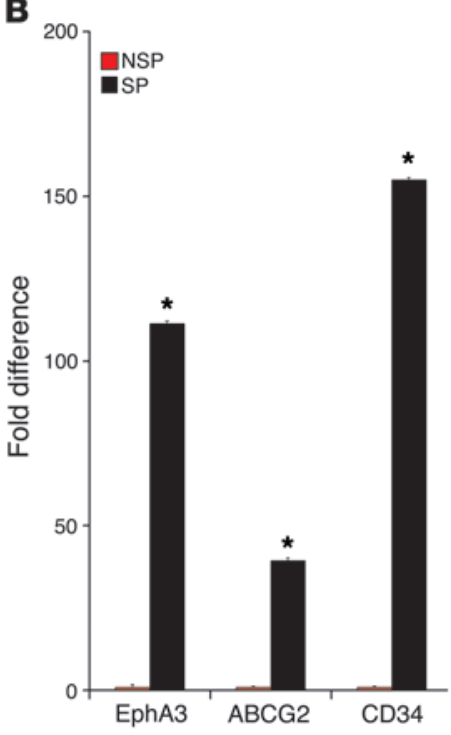

C

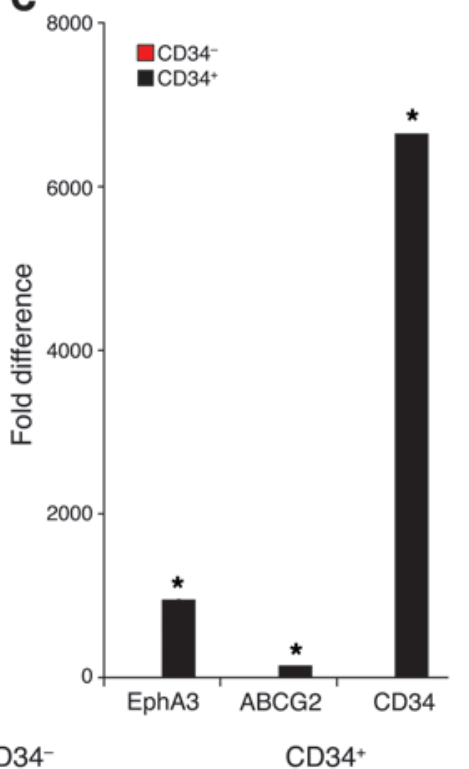

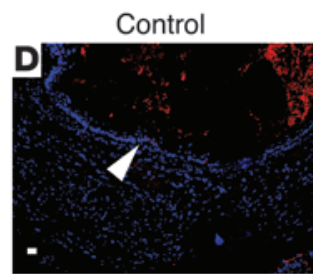
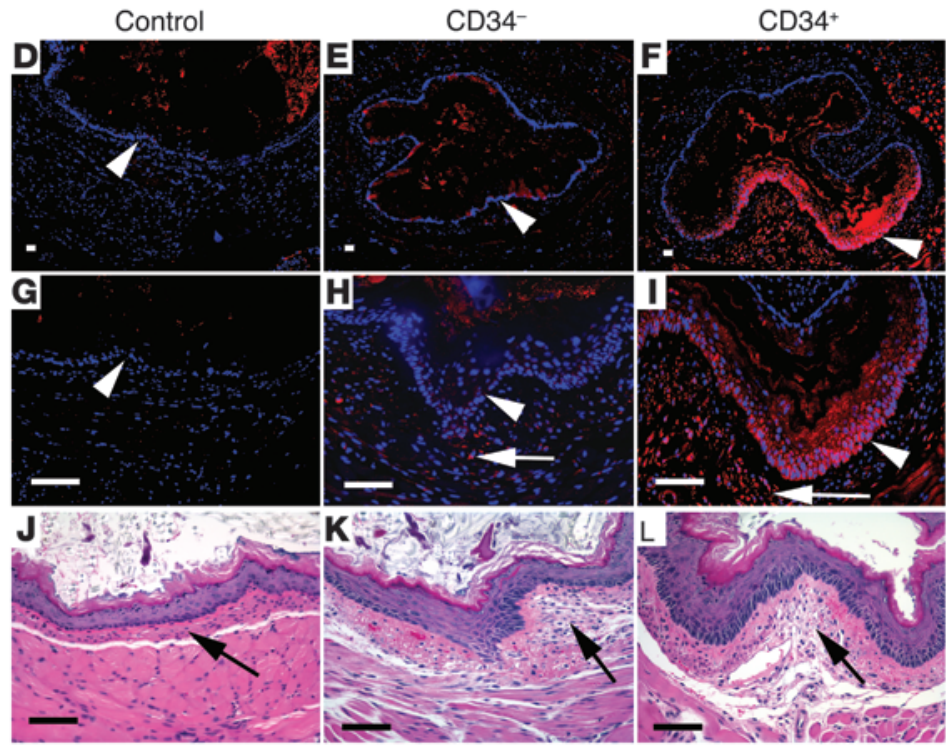

Figure 7

$\mathrm{CD}^{+} 4^{+} \mathrm{GFP}+$ cells have the capacity to contribute to esophageal epithelial restitution after induction of injury. $(\mathbf{A}) \mathrm{CD}^{2} 4^{+}$(green) or CD34- (red) esophageal epithelial cells were $\mathrm{CK}^{+}(94.8 \% \pm 1.66 \%$ or $91.24 \% \pm 1.38 \%$ by FACS, respectively; data not shown), and nuclei were stained with DAPI (blue). Original magnification, $\times 1,000$. Scale bars: $5 \mu \mathrm{m}$. (B) Comparison of selected markers (CD34, ABCG2, EphA3) in SP cells normalized to NSP cells by RT-PCR ( ${ }^{\star} P<0.01$ compared with NSP; $n=3$ experiments). (C) Comparison of selected markers in CD34+ cells normalized to CD34- cells by RT-PCR ( ${ }^{*}<<0.01$ compared with CD34-; $n=3$ experiments). In B and C, data are mean \pm SEM. (D, G, and J) PBS (control) was injected in the submucosa after mucosal injury. The epithelium reformed after 48 hours. There were no GFP + cells (red) in PBS-injected tissues. $(\mathbf{E}, \mathbf{H}$, and $\mathbf{K})$ CD34-GFP+ cells $\left(3 \times 10^{4}\right)$ were injected into the submucosa after induction of mucosal injury. The epithelium re-formed after 48 hours. There were few GFP+ cells (red) in the epithelium. $(\mathbf{F}, \mathbf{I}$, and $\mathbf{L})$ CD $34^{+} \mathrm{GFP}+{ }^{+}$cells $\left(3 \times 10^{4}\right)$ were injected into the submucosa after induction of mucosal injury. The epithelium re-formed after 48 hours. The re-formed epithelium was GFP+, consistent with the migration of stem cells and emergence of differentiated lineages. Some GFP+ cells remained in the submucosa. Arrowheads indicate basement membrane. Arrows indicate site of cell injection in the submucosa. Original magnification, $\times 40$ (D-F); $\times 100$ (G-L). Scale bars: $25 \mu \mathrm{m}$.

33342 staining. Antibodies used in this study were CD49f-FITC (1:200), CD71-RPE (1:200), CD34-FITC (1:200), CD34-PE (1:400), Ly-6A/E-FITC (1:200), and CD45-FITC (1:200) (all BD Biosciences - Pharmingen).

Immunohistochemistry. Tissues were fixed in $4 \%$ PFA, embedded in paraffin and cut $6 \mu \mathrm{m}$ thick. Sections were mounted on adhesive-coated slides, deparaffinized, and rehydrated through xylene and alcohol. For BrdU anti- gen retrieval, tissues were incubated in $10 \mathrm{mM}$ of citric acid buffer (Fisher, $\mathrm{pH}$ 6.0) for 14 minutes in a microwave oven at full power. After rinsing in tap water and PBS, endogenous peroxidase was blocked with $1.5 \% \mathrm{H}_{2} \mathrm{O}_{2}$ in $\mathrm{dH}_{2} \mathrm{O}$ for 15 minutes at room temperature (RT). Sections were blocked with avidin D, biotin (Blocking Kit; Vector Laboratories Inc.), and Protein Blocking Agent (Immunotech) for 15 minutes at RT. They were incubated 
with a mouse anti-BrdU antibody (Roche Diagnostics) diluted 1:500 in Tween-20 in PBS (PBT) for 45 minutes at $37^{\circ} \mathrm{C}$, washed with PBS, and conjugated with a biotinylated horse anti-mouse antibody (Vector Laboratories Inc.), diluted 1:100 in PBS, for 30 minutes at RT and developed with the $\mathrm{ABC}$ Elite reagent (Vectastain $\mathrm{ABC}$ Kit; Vector Laboratories Inc.) with diaminobenzidine tetrahydrochloride as a substrate (DAB substrate kit; Vector Laboratories Inc.) according to the manufacturer's instructions, and counterstained with $\mathrm{H} \& \mathrm{E}$. Antibodies and reagents were used at the following dilutions or concentrations: GFP (1:200; Novus Biologicals), CD34 (MEC14.7, 1:10; Novus Biologicals), pan-CK type II, CK-1l (1:200; Chemicon), and BrdU (US Biological).

Immunofluorescence. Sections were prepared as described for immunohistochemistry. Sections were incubated with a sheep anti-BrdU antibody (1:500; US Biological), anti-CD34 antibody, rabbit anti-CK14 (1:3,000; Covance), mouse anti-CK4 (Vector laboratories), rabbit anti-GFP (1:5,000; Abcam), mouse anti-Ki67 (1:1,000; Novocastra), and mouse anti-pan-CK antibody (1:3,000; Sigma-Aldrich) in PBT overnight at $4^{\circ} \mathrm{C}$. After PBS washes, sections were incubated with Cy3-conjugated donkey anti-sheep IgG (Jackson ImmunoResearch Laboratories Inc.) diluted 1:300 in PBS and Cy2-conjugated donkey anti-mouse IgG (Jackson ImmunoResearch Laboratories Inc.) diluted 1:300 in PBS for 30 minutes at $37^{\circ} \mathrm{C}$. After PBS washes, sections were incubated with DAPI (1:10,000; Invitrogen) for 10 seconds at RT for nucleic acid staining.

Immunocytochemistry. SP and NSP cells were sorted by FACScan. Then cells were attached to glass slides by cytospin ( $350 \mathrm{~g}$ for 10 minutes). Sorted cells were fixed with $10 \%$ formalin and immunohistochemically stained with BrdU. The number of $\mathrm{BrdU}^{+}$cells was counted under a microscope.

Confocal microscopy. The image stacks of roughly $15 \mu \mathrm{m}$ through the $z$ dimension, at steps $1.0 \mathrm{~mm}$ apart, were obtained sequentially for each fluorescent channel using a Zeiss C-Apo 40×W 1.2 DIC lens, mounted on a laser scanning confocal microscope (LSM 410 equipped Axiovert 135; Carl Zeiss). The 488-nm laser line of an Omnichrome argon/krypton ion laser for excitation and a 515- to 565-nm band-pass filter for the emission (FITC), as well as the 351- and 364-nm laser lines of a Coherent Enterprise argon ion laser for excitation and a 410- to 505-nm band-pass filter were used for the emission (DAPI). Later, maximum intensity "throughfocus" projections of the image stacks were generated in post-processing, and contrast stretching was applied uniformly across images from each channel. For acquisition, we used Zeiss LSM version 3.98 software, and for post-acquisition 3D projections, we used Zeiss LSM Image Examiner version 2.8 software.

Microarray analysis. mRNA was isolated from sorted SP and NSP cells using RNeasy kit (Qiagen), amplified using RiboAmp OA RNA amplification kit (Arcturus Bioscience), and processed for microarray analysis using MOE-430A Affymetrix GeneChip probe array according to the manufacturer's instructions.

Quantitative real-time PCR. mRNA was isolated from sorted cells by using the RNeasy kit (Qiagen) and reverse transcribed into cDNA with SuperScript III (Invitrogen) as per the manufacturer's instructions. Primers for SYBR Green real-time PCR were designed using the TaqMan probe software and synthesized by Invitrogen. Gene-specific primers for mouse genes were as follows: ABCG2, 5'-AGACCGCCATGTCCACTGTT-3' (forward), 5'-TGGTCGCACACCACATCTTT-3' (reverse); CD34, 5'-GGACGATGCCTGCAACGT-3' (forward), 5'-ACAAATACAGCTGGTTCCCAATC-3' (reverse); and GAPDH, 5'-CACCCACTCCTCCACCTTT-3' (forward), 5'-TCCACCACCCTGTTGCTGTAG-3' (reverse). These primers were optimized for expression analyses by real-time PCR on the ABI 7500 thermocycler (Applied Biosystems), using ABsolute QPCR SYBR Green ROX Mix (ABgene), for 2 minutes at $50^{\circ} \mathrm{C}, 15$ minutes at $95^{\circ} \mathrm{C}, 40$ cycles of 15 seconds at $95^{\circ} \mathrm{C}$, and 1 minute at $60^{\circ} \mathrm{C}$, followed by dissociation-curve analy- sis to confirm specificity. GAPDH was used as an internal control. SYBR Green real-time PCR was performed and analyzed using ABI PRISM 7000 Sequence Detection System software (Applied Biosystems) with reagents from the SYBR Green PCR Kit (Applied Biosystems) according to the manufacturer's instructions. GAPDH and $\mathrm{H}_{2} \mathrm{O}$ were used as positive and negative controls, respectively. Relative expression was calculated using the comparative CT method.

Colony formation assay. The SP, NSP, CD34+, and CD34- cells were isolated and sorted by flow cytometry. One thousand cells were seeded onto irradiated Swiss $3 \mathrm{~T} 3$ cells in $60-\mathrm{mm}$ dishes and grown at $32^{\circ} \mathrm{C}$ with $5 \% \mathrm{CO}_{2}$ in William's E medium (Life Technologies) containing $20 \%$ FBS, gentamycin, and supplements. Cultures were grown for 2 weeks, fixed in $10 \%$ formalin, and then stained with $1 \%$ rhodamine $\mathrm{B}$ to visualize colony growth. The remaining cultures were grown for an additional 2 weeks and then fixed and stained as described above. Colony size was measured using duplicate populations per experiment $(n=3)$.

Intraepidermal cyst formation assay. The SP and NSP epithelial cells were isolated from nude (nu/nu) mice (Charles River Laboratories). Mice were anesthetized with a combination of ketamine at $100 \mathrm{mg} / \mathrm{kg}$ (Fort Dodge Animal Health) and xylazine at $10 \mathrm{mg} / \mathrm{kg}$ (Phoenix Scientific). Unless otherwise stated, for each intraepidermal injection, $10^{6}$ dermal cells and $10^{4}$ epidermal aggregates (which on average produce $0.5 \times 10^{6}$ single epidermal cells) were resuspended (50-70 $\mu$ l of DMEM-F12 medium; Invitrogen) and injected with a 25 -gauge needle into the hypodermis of the mouse skin, forming a bleb (26). The injection site was marked by a black tattoo puncture (242 Permanent Black Pigment; Aims). Harvested mouse skins were fixed in $10 \%$ formalin overnight. After paraffin embedding, the tissues were processed for histology and immunostaining (26).

Organotypic culture. Organotypic cultures were prepared as described (25). Freshly isolated SP or NSP cells were seeded on top of collagen ECM gels with embedded fetal esophageal fibroblasts. Cultures were grown on LabTek 8-well chambers or tissue culture inserts in KBSM supplemented with $8 \mathrm{mmol} \mathrm{Ca}{ }^{2+}$. For serial passage, epithelial cells were harvested from primary organotypic cultures, and secondary organotypic cultures were prepared in the same fashion.

Esophageal injury model in vivo tissue reconstitution. The ability of the CD $34^{+}$ cell populations to regenerate a stratified epithelium was assessed using an in vivo esophageal transplantation model. Nude mice were operated under ketamine/xylazine anesthesia. The lower esophagus was accessed through the stomach, and a dental tool was used to induce mucosal injury to the lower esophagus. Freshly sorted $\mathrm{CD} 34^{+}$or $\mathrm{CD} 34^{-}$cells $\left(10^{5}\right)$ from GFP mice were resuspended in $30 \mu \mathrm{l}$ of KSFM with supplements and implanted to the submucosa under the injured mucosa. No carrier cell populations were used. The implanted esophagi were harvested at 12, 24, and 48 hours after implantation, fixed by $4 \%$ PFA, and processed for histology and immunostaining or snap-frozen and processed for fluorescent imaging. GFP expression was detected in paraffin-embedded samples using immunofluorescence with an anti-GFP antibody (Invitrogen) (40).

Bone marrow transplantation. Whole bone marrow cells were isolated from the femurs and tibias of 6- to 8-week-old ROSA26-EGFP mice of FVB/N background (Mutant Mouse Regional Resource Center) (41). Isolated cells were washed and passed through a $40-\mu \mathrm{m}$ nylon mesh cell strainer (BD Biosciences) to produce a single-cell suspension in Hank's balanced salt solution (Invitrogen). Recipient mice, also of FVB/N background (2-3 months of age), were irradiated with 12 Gy (2 divided doses of 6 Gy each, separated by a 3-hour interval) from a Cesium-137 Gammacell 40 irradiator (MDS Nordion) and reconstituted with $2-3 \times 10^{6}$ whole bone marrow cells from ROSA26-EGFP donor mice via a single tail vein injection. After recovery, the recipient mice were sacrificed 7 months following irradiation, and the tissues were extracted and fixed in 4\% PFA (Alfa Aesar) overnight. 
The tissues were soaked in 30\% sucrose (Thermo Fisher Scientific) overnight and embedded in OCT compound (Sakura), and frozen sections were cut. The overall level of bone marrow engraftment was confirmed to be more than $95 \% \mathrm{GFP}^{+}$cells in recipient mice at autopsy, as analyzed by FACS LSRII (BD Biosciences).

Statistics. The 2-tailed Student's $t$ test was used. A P value of less than 0.05 was considered to be statistically significant.

\section{Acknowledgments}

This work was supported by grants from the NCI (P01 DE12467, to A.K. Rustgi, J. Kalabis, H. Nakagawa, C. Michaylira, D.B. Stairs, M. Herlyn, and J.A. Diehl; CA80999 and CA25874, to M. Herlyn), the NIDDK Center for Molecular Studies in Digestive and Liver Diseases (P30 DK50306, to A.K. Rustgi), and the NIH (K01DK0662059 and R01-DK077005, to H. Nakagawa); and by the NIH National Research Service Award (F32 grants, to C. Michaylira and D.B. Stairs). This work was also supported by S. Mitchell (Mor- phology Core Facility), Don Baldwin (Microarray Core Facility), Jonni Moore and Hank Fletcher (Flow Cytometry Core Facility), and the Molecular Biology, Mouse, Cell Culture, and Biomedical Imaging Core Facilities. We thank members of the Rustgi lab for discussions, George Cotsarelis and Gwenn-aël Danet-Desnoyers for review of the manuscript, and Ben Rhoades.

Received for publication January 14, 2008, and accepted in revised form October 1, 2008.

Address correspondence to: Anil K. Rustgi, University of Pennsylvania, 600 CRB, 415 Curie Blvd., Philadelphia, Pennsylvania 19104, USA. Phone: (215) 898-0154; Fax: (215) 573-2024; E-mail: anil2@mail.med.upenn.edu.

Jiri Kalabis, Kenji Oyama, and Takaomi Okawa contributed equally to this work and are co-first authors.
1. Wagner, W., et al. 2004. Molecular evidence for stem cell function of the slow-dividing fraction among human hematopoietic progenitor cells by genome-wide analysis. Blood. 104:675-686.

2. Cairnie, A., Lala, P., and Osmond, D. 1976. Stem cells of renewing cell populations. Academic Press. New York, New York, USA. 225-261.

3. Potten, C., and Lord, B. 1983. Stem cells: their identification and characterization. Churchill Livingstone. London, United Kingdom. 200-232.

4. Potten, C. 1997. Stem cells. Academic Press. London, United Kingdom. 1-27.

5. Potten, C.S., and Bullock, J.C. 1983. Cell kinetic studies in the epidermis of the mouse. I. Changes in labeling index with time after tritiated thymidine administration. Experientia. 39:1125-1129.

6. Lavker, R.M., and Sun, T.T. 2000. Epidermal stem cells: properties, markers, and location. Proc. Natl. Acad. Sci. U. S. A. 97:13473-13475.

7. Bickenbach, J.R. 1981. Identification and behavior of label-retaining cells in oral mucosa and skin. J. Dent. Res. 60:1611-1620.

8. Mackenzie, I.C., and Bickenbach, J.R. 1985. Labelretaining keratinocytes and Langerhans cells in mouse epithelia. Cell Tissue Res. 242:551-556.

9. Cotsarelis, G., Sun, T.T., and Lavker, R.M. 1990. Label-retaining cells reside in the bulge area of pilosebaceous unit: implications for follicular stem cells, hair cycle, and skin carcinogenesis. Cell. 61:1329-1337.

10. Shinohara, T., Avarbock, M.R., and Brinster, R.L. 1999. beta1- and alpha6-integrin are surface markers on mouse spermatogonial stem cells. Proc. Natl. Acad. Sci. U. S. A. 96:5504-5509.

11. Tani, H., Morris, R.J., and Kaur, P. 2000. Enrichment for murine keratinocyte stem cells based on cell surface phenotype. Proc. Natl. Acad. Sci. U. S. A. 97:10960-10965.

12. Jones, P.H., and Watt, F.M. 1993. Separation of human epidermal stem cells from transit amplifying cells on the basis of differences in integrin function and expression. Cell. 73:713-724.

13. Bickenbach, J.R., and Chism, E. 1998. Selection and extended growth of murine epidermal stem cells in culture. Exp. Cell Res. 244:184-195.

14. Leblond, C.P. 1964. Classification of Cell Populations on the Basis of Their Proliferative Behavior. Natl. Cancer Inst. Monogr. 14:119-150.

15. Seery, J.P., and Watt, F.M. 2000. Asymmetric stem- cell divisions define the architecture of human oesophageal epithelium. Curr. Biol. 10:1447-1450.

16. Goodell, M.A., Brose, K., Paradis, G., Conner, A.S. and Mulligan, R.C. 1996. Isolation and functional properties of murine hematopoietic stem cells that are replicating in vivo. J. Exp. Med. 183:1797-1806.

17. Terunuma, A., Jackson, K.L., Kapoor, V., Telford, W.G., and Vogel, J.C. 2003. Side population keratinocytes resembling bone marrow side population stem cells are distinct from label-retaining keratinocyte stem cells. J. Invest. Dermatol. 121:1095-1103.

18. Yano, S., et al. 2005. Characterization and localization of side population cells in mouse skin. Stem Cells. 23:834-841.

19. Redvers, R.P., Li, A., and Kaur, P. 2006. Side population in adult murine epidermis exhibits phenotypic and functional characteristics of keratinocyte stem cells. Proc. Natl. Acad. Sci. U. S. A. 103:13168-13173.

20. Welm, B.E., et al. 2002. Sca-1(pos) cells in the mouse mammary gland represent an enriched progenitor cell population. Dev. Biol. 245:42-56.

21. Lechner, A., Leech, C.A., Abraham, E.J., Nolan, A.L., and Habener, J.F. 2002. Nestin-positive progenitor cells derived from adult human pancreatic islets of Langerhans contain side population (SP) cells defined by expression of the ABCG2 (BCRP1) ATPbinding cassette transporter. Biochem. Biophys. Res. Commun. 293:670-674.

22. Potten, C.S., Kellett, M., Roberts, S.A., Rew, D.A and Wilson, G.D. 1992. Measurement of in vivo proliferation in human colorectal mucosa using bromodeoxyuridine. Gut. 33:71-78.

23. Goodell, M.A., et al. 2001. Stem cell plasticity in muscle and bone marrow. Ann. N. Y. Acad. Sci. 938:208-218; discussion 218-220.

24. Jackson, K.A., Mi, T., and Goodell, M.A. 1999. Hematopoietic potential of stem cells isolated from murine skeletal muscle. Proc. Natl. Acad. Sci. U. S. A. 96:14482-14486.

25. Okawa, T., et al. 2007. The functional interplay between EGFR overexpression, hTERT activation, and p53 mutation in esophageal epithelial cells with activation of stromal fibroblasts induces tumor development, invasion, and differentiation. Genes Dev. 21:2788-2803.

26. Nakamura, Y., et al. 2006. Expression of CD90 on keratinocyte stem/progenitor cells. Br. J. Dermatol. 154:1062-1070.

27. Cotsarelis, G., Kaur, P., Dhouailly, D., Hengge, U., and Bickenbach, J. 1999. Epithelial stem cells in the skin: definition, markers, localization and functions. Exp. Dermatol. 8:80-88.

28. Ito, M., et al. 2005. Stem cells in the hair follicle bulge contribute to wound repair but not to homeostasis of the epidermis. Nat. Med. 11:1351-1354.

29. Rochat, A., Kobayashi, K., and Barrandon, Y. 1994. Location of stem cells of human hair follicles by clonal analysis. Cell. 76:1063-1073.

30. Lavker, R.M., and Sun, T.T. 1982. Heterogeneity in epidermal basal keratinocytes: morphological and functional correlations. Science. 215:1239-1241.

31. Braun, K.M., et al. 2003. Manipulation of stem cell proliferation and lineage commitment: visualisation of label-retaining cells in wholemounts of mouse epidermis. Development. 130:5241-5255.

32. Morris, R.J., et al. 2004. Capturing and profiling adult hair follicle stem cells. Nat. Biotechnol. 22:411-417.

33. Alvi, A.J., et al. 2003. Functional and molecular characterisation of mammary side population cells. Breast Cancer Res. 5:R1-R8.

34. Barker, N., et al. 2007. Identification of stem cells in small intestine and colon by marker gene Lgr5. Nature. 449:1003-1007.

35. Jaks, V., et al. 2008. Lgr5 marks cycling, yet long-lived, hair follicle stem cells. Nat. Genet. 40:1291-1299.

36. Poblet, E., Jimenez, F., Godinez, J.M., Pascual-Martin, A., and Izeta, A. 2006. The immunohistochemical expression of CD34 in human hair follicles: a comparative study with the bulge marker CK15. Clin. Exp. Dermatol. 31:807-812.

37. Trempus, C.S., et al. 2007. CD34 expression by hair follicle stem cells is required for skin tumor development in mice. Cancer Res. 67:4173-4181.

38. Drew, E., Merzaban, J.S., Seo, W., Ziltener, H.J., and McNagny, K.M. 2005. CD34 and CD43 inhibit mast cell adhesion and are required for optimal mast cell reconstitution. Immunity. 22:43-57.

39. Clayton, E., et al. 2007. A single type of progenitor cell maintains normal epidermis. Nature. 446:185-189.

40. Swenson, E.S., Price, J.G., Brazelton, T., and Krause, D.S. 2007. Limitations of green fluorescent protein as a cell lineage marker. Stem Cells. 25:2593-2600.

41. Kisseberth, W.C., Brettingen, N.T., Lohse, J.K., and Sandgren, E.P. 1999. Ubiquitous expression of marker transgenes in mice and rats. Dev. Biol. 214:128-138. 